\title{
PENAMBAHAN CORE STABILITY PADA STAR EXCURSION BALANCE EXERCISE LEBIH MENINGKATKAN KESEIMBANGAN DINAMIS DAN MENURUNKAN FUNGSIONAL ANKLE INSTABILITAS DARIPADA STAR EXCURSION BALANCE EXERCISE PADA BELA DIRI TAEKWONDO
}

Anak Agung Gede Eka Septian Utama ${ }^{1}$, Putu Astawa², Muh. Ali Imron ${ }^{3}$, Tjokorda Gde Bagus Mahadewa ${ }^{4}$, Bagus Komang Satriyasa ${ }^{5}$, Desak Made Wihandani ${ }^{6}$

${ }^{1}$ Program Magister S2 Fisiologi Keolahragaan, Fakultas Kedokteran, Universitas Udayana, Denpasar

${ }^{2}$ Departemen Orthopedi dan Traumatologi, Fakultas Kedokteran, Universitas Udayana, Denpasar

${ }^{3}$ Fakultas Fisioterapi Universitas Aisyiyah, Yogyakarta

${ }^{4}$ Departemen Bedah Saraf, Fakultas Kedokteran, Universitas Udayana, Denpasar

${ }^{5}$ Departemen Farmakologi, Fakultas Kedokteran, Universitas Udayana, Denpasar

${ }^{6}$ Departemen Biokimia, Fakultas Kedokteran, Universitas Udayana, Denpasar

Email : gungeka24@yahoo.com

\begin{abstract}
ABSTRAK
Latar belakang: Taekwondo merupakan bela diri yang banyak menggunakan anggota gerak bawah terutama pergelangan kaki sehingga sering terjadi fungsional ankle instabilitas (FAI). FAI terjadi akibat adanya gangguan dari postural kontrol, keseimbangan dinamis dan fungsi otot. Salah satu latihan yang dapat dipergunakan adalah star excursion balance exercise, namun masih ada kekurangan dalam kontrol postural akibat tidak terjadi aktivasi otot core untuk pembentukan postural stabilisasi. Tujuan: Untuk membuktikan penambahan core stability pada star excursion balance exercise lebih meningkatkan keseimbangan dinamis dan menurunkan fungsional ankle instabilitas daripada star excursion balance exercise pada bela diri taekwondo. Metode: Rancangan penelitian ini adalah randomized pretest-postest control group design, Kelompok 1 mendapatkan star excursion balance exercise dan Kelompok 2 mendapatkan core stability dan star excursion balance exercise. Fungsional ankle instabilitas diukur menggunakan cumberland ankle instability tool (CAIT) dan keseimbangan dinamis menggunakan star excursion balance test (SEBT). Dilakukan 3 kali seminggu selama 6 minggu. Hasil: Peningkatan SEBT sebelum pelatihan pada Kelompok 1 sebesar $86,4 \pm 6,3 \mathrm{~cm}$, setelah pelatihan sebesar $92,3 \pm 6,7 \mathrm{~cm}$ dan pada Kelompok 2 sebelum sebesar 86,2 $\pm 6,1 \mathrm{~cm}$, setelah pelatihan sebesar $96,7 \pm 7,9 \mathrm{~cm}$. Penurunan fungsional ankle instabilitas dari peningkatan nilai CAIT sebelum

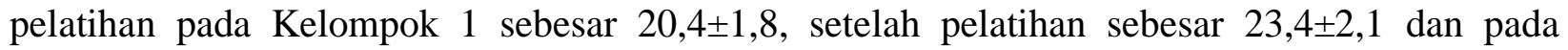
Kelompok 2 sebelum sebesar 20,3 $\pm 2,8$, setelah pelatihan sebesar 25,0 $\pm 1,9$. Perbedaan peningkatan keseimbangan dinamis pada Kelompok 1 dan 2 bermakna $(p<0,05)$. Perbedaan penurunan FAI pada Kelompok 1 dan 2 bermakna $(\mathrm{p}<0,05)$. Kesimpulan: Penambahan core stability pada star excursion balance exercise lebih meningkatkan keseimbangan dinamis dan menurunkan fungsional ankle instabilitas daripada star excursion balance exercise pada bela diri taekwondo.
\end{abstract}


Kata kunci: fungsional ankle instabilitas, keseimbangan dinamis, star excursion balance exercise, core stability.

\section{ADDITIONAL CORE STABILITY IN STAR EXCURSION BALANCE EXERCISE INCREASING DYNAMIC BALANCE AND REDUCING FUNCTIONAL ANKLE INSTABILITY THAN STAR EXCURSION BALANCE EXERCISE IN TAEKWONDO}

\section{ABSTRACT}

Background: taekwondo is a martial art that uses a lot of lower limbs especially ankle so that functional ankle instability (FAI) often occurs. FAI occurs due to postural control, dynamc balance, and muscle function. One of the exercises that could be used was star excursion balance exercise; however there are still deficiencies in postural control as a result of no activation of the core muscle for the formation of postural stabilization. Objective: To know the addition of core stability to star excursion balance exercise further increases dynamic balance and decreases ankle functional instability than star excursion balance exercise in taekwondo martial arts. Method: This study used a randomized pretest-posttest control group design, group I received star excursion balance exercise and group II received core stability and star excursion balance exercise. Functional ankle instability was measured using the cumberland ankle instability tool (CAIT) and dynamic balance uses the star excursion balance test (SEBT). This research was carried out three times a week for 6 weeks. Results: the increase in dynamic balance before training in group 1 was $86.4 \pm 6.3$, after training it was $92.3 \pm 6.7$, and in group 2 before training it was $86.2 \pm 6.1$, after training was $96.7 \pm 7.9$ The decreased in Functional ankle instability before training in group 1 was $20.4 \pm 1.8$, after training it was $23.4 \pm 2.1$, and in group 2 before training it was $20.3 \pm 2.8$, after training was $25.0 \pm 1.9$. The comparison of dynamic balance in groups 1 and 2 is meaningful ( $\mathrm{p}<0.05$ ). The comparison of dynamic balance in groups 1 and 2 is meaningful ( $p$ $<0.05)$. Conclusion: Adding core stability to star excursion balance exercise increases dynamic balance and decreases ankle functional instability than star excursion balance exercise in taekwondo martial arts.

Keywords: functional ankle instability, dynamic balance, star excursion balance exercise, core stability.

\section{PENDAHULUAN}

Taekwondo didasarkan pada serangan mendadak dan keras menggunakan tendangan sehingga memerlukan kemampuan dari anggota gerak bawah terutama pergelangan kaki. ${ }^{1}$ Anggota gerak bawah menjadi cidera yang paling sering yaitu sebesar $46,5 \%$ dan sprain ankle menyumbang $15 \%$ sampai $20,8 \%$ dari cedera pada taekwondoin. ${ }^{2,3}$ Diperkirakan $72 \%$ yang mengalami sprain ankle berkembang menjadi fungsional ankle instabilitas. $^{4}$

Fungsional ankle instabilitas ditandai dengan adanya rasa instabil atau "giving away" yang terus menerus dan dapat terjadi ankle sprain berulang. Permasalahan yang sering ditemukan pada kondisi ini adalah gangguan dalam postural kontrol, 
keseimbangan dinamis dan fungsi otot. ${ }^{4,5}$ Meningkatkan kemampuan keseimbangan dinamis sangat penting secara klinis untuk memperbaiki instabilitas anggota gerak bawah. ${ }^{6}$ Salah satu latihan yang sering digunakan adalah star excursion balance exercise.

Star excursion balance exercise memiiki prinsip close chain kinematic yang akan menyebabkan terjadinya kontraksi konsentris dan eksentris pada otot secara bersamaan, stimulasi proprioseptif, meningkatkan kontrol postural dan koordinasi. ${ }^{7}$ Didukung oleh penelitian Chaiwanichsiri ${ }^{8}$, yang menyimpulkan bahwa star excursion balance exercise sangat efektif dalam meningkatkan fungsional stabilisasi pada ankle sprain dan keseimbangan dinamis selama 4 minggu. Dilaporkan juga dalam 3 bulan di follow up masih ada beberapa yang mengalami kejadian ankle sprain berulang akibat keseimbangan dinamis dan fungsional ankle instabil belum terjadi perbaikan secara sempurna terutama kontrol postural.

Mekanisme kontrol postural optimal pada star excursion balance exercise akibat kontraksi otot pergelangan kaki dan otot global tubuh yang menyebabkan kontrol postural lokal, sehingga tidak tercipta postural stabilitas yang berfungsi dalam menciptakan kontrol postural pada fungsional ankle instabil dan dalam mempertahankan keseimbangan dinamis. ${ }^{9}$ Pada penelitian Hiller ${ }^{10}$, ditemukan penurunan yang signifikan terhadap postural stability pada individu dengan ankle sprain berulang. Oleh karena itu memperhatikan postural stabilitas dalam meningkatkan postural kontrol sangat penting, salah satunya dengan latihan core stability.

Core stability akan mengaktivasi otot core sebagai komponen stabilisasi pada trunk dan pelvis terhadap pola gerakan ekstremitas yang berfungsi dalam postural stabilisasi untuk menciptakan postural kontrol. ${ }^{11}$ Sehingga sangat baik dikombinasikan untuk memperbaiki fungsional ankle instabilitas karena mekanismenya saling bersinergi dan membantu dalam meningkatkan komponen fungsional ankle instabilitas serta dalam meningkatkan keseimbangan dinamis.

Berdasarkan latar belakang diatas, penelitian ini mengambil judul "penambahan core stability pada star excursion balance exercise lebih meningkatkan keseimbangan dinamis dan menurunkan fungsional ankle instabilitas daripada star excursion balance exercise pada bela diri taekwondo".

\section{METODE PENELITIAN}

\section{Desain Penelitian}

Penelitian ini menggunakan rancangan randomized pretest-posttest control group design. Subjek dibagi menjadi dua, Kelompok 1 mendapatkan star excursion balance exercise sedangkan Kelompok 2 mendapatkan core stability dan star excursion balance exercise.

Penelitian dilakukan di Dojang Underdog Taekwondo Denpasar terhitung dari bulan April-Juni 2019, dilakukan sebanyak 18 kali. Populasi terjangkau adalah taekwondoin Dojang Underdog Taekwondo Club Denpasar yang sudah memenuhi kriteria inklusi seperti Laki-laki usia 13-24 tahun berstatus sebagai pelajar, IMT normal, nilai CAIT <24, dan memiliki kekuatan otot core <224 detik dengan pengukuran 60 derajat fleksi tes. Penelitian dilakukan 
dengan frekuensi 3 kali seminggu selama 6 minggu dengan jumlah sampel 16 di masing-masing.

\section{HASIL PENELITIAN}

\section{Karakteristik Sampel}

Karakteristik sampel dalam penelitiain ini terdiri dari umur, IMT, CAIT awal dan kekuatan otot core awal dipaparkan pada Tabel 1.

Berdasarkan Tabel 1. Karakteristik rerata umur pada Kelompok 1 dan Kelompok 2 mendapatkan nilai p>0,05. Pada rerata IMT pada Kelompok 1 dan Kelompok 2 mendapatkan nilai p>0,05 yang berarti tidak ada perbedaan. Untuk fungsional ankle instabilitas awal pada kelompok 1 dan kelompok 2 mendapatkan nilai $\mathrm{p}>0,05$ yang memiliki arti tidak ada perbedaan. Untuk kekuatan otot core awal pada kelompok 1 dan kelompok 2 mendapatkan nilai $\mathrm{p}>0,05$.

Tabel 1.

Karakteristik sampel

\begin{tabular}{cccc}
\hline \multirow{2}{*}{$\begin{array}{c}\text { Karakteri } \\
\text { stik } \\
\text { Sampel }\end{array}$} & Kelompok 1 & Kelompok 2 & \\
\cline { 2 - 4 } & \multicolumn{2}{c}{ Rata-rata \pm SD } & \\
\hline $\begin{array}{c}\text { Umur } \\
\text { (thn) }\end{array}$ & $15,63 \pm 2,92$ & $16,13 \pm 2,96$ & 0,502 \\
IMT & $21,37 \pm 2,475$ & $20,99 \pm 2,669$ & 0,684 \\
$(\mathrm{~kg} / \mathrm{m} 2)$ & & & \\
CAIT & $20,4 \pm 1,8$ & & 0,575 \\
$\begin{array}{c}\text { awal } \\
(\text { skor })\end{array}$ & & & \\
$\begin{array}{c}\text { Kekuatan } \\
\text { otot core } \\
\text { awal (s) }\end{array}$ & $167,50 \pm 31,38$ & $167,75 \pm 29,64$ & 0,940 \\
\hline
\end{tabular}

\section{Uji Normalitas dan Homogenitas}

Hasil dari analisis normalitas menggunakan Saphiro-Wilk test dan homogenitas menggunakan Levene's Test. Normalitas pada keseimbangan dinamis untuk Kelompok 1 sebelum sebesar 0,830, setelah sebesar 0,779 dan selisih sebesar 0,930. Untuk Kelompok 2 sebelum sebesar 0,007, setelah sebesar 0,001 dan selisih sebesar 0,241. Homogenitas sebelum sebesar 0,785, setelah 0,786 dan selisih 0,894 .

Normalitas pada fungsional ankle instabilitas untuk Kelompok 1 sebelum sebesar 0,477, setelah sebesar 0,493, dan selisih sebesar 0,269. Kelompok 2 sebelum sebesar 0,000, setelah sebesar 0,057 dan selisih sebesar 0,036. Homogenitas sebelum sebesar 0,073, seteah sebesar 2,271 dan selisih sebesar 3,701.

\section{Pengujian Hipotesis}

Uji Hipotesis Keseimbangan Dinamis

Hasil uji peningkatan keseimbangan dinamis tertera pada Tabel 2 .

\section{Tabel 2.}

Uji Peningkatan keseimbangan dinamis

\begin{tabular}{cccc} 
& Sebelum & Sesudah & p \\
\hline Klp 1 & $86,4 \pm 6,3$ & $92,3 \pm 6,7$ & 0,000 \\
Klp 2 & $86,2 \pm 6,1$ & $96,7 \pm 7,9$ & 0,000 \\
\hline
\end{tabular}

Berdasarkan Tabel 2. memperlihatkan peningkatan keseimbangan dinamis pada kedua kelompok mendapatkan nilai $\mathrm{p}<0,05$. 


\section{Uji Beda Rerata penurnan fungsional ankle instabilitas}

Hasil beda penurunana fungsional ankle instabilitas tertera pada Tabel 3.

Tabel 3.

Peenurunan fungsional ankle instabilitas

Sebelum dan Setelah Pelatihan

\begin{tabular}{cccc}
\hline & Sebelum & Setelah & $\mathrm{p}$ \\
\hline $\mathrm{Klp}$ & $20,4 \pm 1,8$ & $23,4 \pm 2,1$ & 0,000 \\
1 & & & \\
$\mathrm{Klp}_{2}$ & $20,3 \pm 2,8$ & $25,0 \pm 1,9$ & 0,000 \\
\hline
\end{tabular}

Berdasarkan Tabel 3. di atas, rerata penurunan fungsional ankle instabilitas pada kedua kelompok mendapatkan nilai $\mathrm{p}<0,05$.

\section{Uji Komparasi Hasil Peningkatan Keseimbangan Dinamis}

Hasil Komparasi Hasil Peningkatan

Keseimbangan Dinamis tertera pada Tabel 4.

Tabel 4.

Mann-Whitney U test

\begin{tabular}{ccc}
\hline & Rerata & $\mathrm{p}$ \\
\hline Selisih 1 & $5,9 \pm 1,0$ & 0 \\
Selisih 2 & $10,4 \pm 3,6$ & 000 \\
\hline
\end{tabular}

Berdasarkan

Tabel

4.

memperlihatkan ada perbedaan peningkatan keseimbangan dinamis. Adapun kelompok yang lebih besar peningkatannya yaitu pada pada kelompok II $(12,14 \%)$ daripada kelompok I $(6,86 \%)$.

\section{Uji Komparasi Hasil Selisih Penurunan} Fungsional Ankle Instabilitas

Hasil Komparasi Hasil Selisih Penurunan Fungsional Ankle Instabilitas tertera pada Tabel 5 .

Tabel 5.

\begin{tabular}{ccc}
\multicolumn{3}{c}{ Mann-Whitney U test } \\
\hline & Rerata & $\mathrm{p}$ \\
\hline Selisih 1 & $2,8 \pm 1,1$ & 0,002 \\
Selisih 2 & $4,1 \pm 0,8$ & \\
\hline
\end{tabular}

Berdasarkan Tabel 5. di atas menunjukkan ada perbedaan pada penurunan fungsional ankle instabilitas. Adapun kelompok yang lebih besar penurunannya yaitu pada kelompok II $(20,22 \%)$ daripada kelompok I $(13,75 \%)$.

\section{PEMBAHASAN}

\section{Karakteristik Sampel}

Distribusi subjek berdasarkan usia pada Kelompok 1 memiliki rerata umur yang tidak berbeda dengan Kelompok 2 . Menurut Mandarakas, et $a .^{12}$, prevalensi penurunan keseimbangan banyak terjadi pada remaja yang aktif dalam olahraga seperti dansa dan permainan bola daripada orang dewasa. Hal ini dikarenakan pada usia tersebut aktif melakukan kegiatan dengan dominasi penggunaan pergelangan kaki yang menyebabkan resiko lebih tinggi pada cedera pergelangan kaki. ${ }^{12}$

Karakteristik sampel berdasarkan IMT tidak ada perbedaan pada grup 1 dan grup 2. Orang yang IMT lebih maupun kurang berpengaruh tehadap kekuatan, kecepatan, dan keseimbangan yang berkaitan dengan center of gravity. ${ }^{14}$ 
Star Excursion Balance Exercise dapat Meningkatkan Keseimbangan Dinamis dan Menurunkan Fungsional Ankle Instabilitas pada Beladiri Taekwondo

Berdasarkan hasil penelitian yang didapatkan pada penelitian ini membuktikan bahwa star excursion balance exercise dapat meningkatkan keseimbangan dinamis dan menurunkan fungsional ankle instabilitas pada bela diri taekwondo

Star excursion balance exercise menyebabkan kontraksi otot secara konsentris dan eksentris, adanya pencapaian kontrol sensorimotor, serta menciptakan hip strategy dengan mengkontraksikan otot paha dan hip untuk menciptakan kontrol postural secara bersamaan. ${ }^{15}$ Latihan star excursion balance akan mempengaruhi kontrol sensorimotor melalui mekanisme proprioseptif yang menginformasikan presisi gerakan dan refleks muscular yang berkontribusi terhadap pembentukan stabilitas dinamis pada sendi dan keseimbangan dinamis serta membangkitkan aktivasi otot pergelangan kaki untuk melatih kekuatan otot stabilisator pergelangan kaki. ${ }^{8}$ Pada penelitian Reza, et al. ${ }^{16}$ yang berjudul "The Effect of Star Excursion Balance Training on Ankle Sprain Injury Rehabilitation" dengan jumlah sampel 16 orang atlet tidak professional yang diberikan latihan selama 4 minggu. Hasilnya latihan Star Excursion Balance Training efektif dalam program rehabilitasi sprain ankle terutama kemampuan keseimbangan.

Didukung dengan penelitian yang dilakukan oleh Chaiwanichsiri ${ }^{8}$, tentang star excursion balance training dalam meningkatkan stabilitas fungsional pergelangan kaki yang terkilir yang dilakukan selama 4 minggu. Hasilnya pada pelatihan Star Excursion Balance lebih efektif daripada program terapi konvensional dalam meningkatkan stabilitas fungsional pergelangan kaki yang terkilir. Akan tetapi dilaporkan juga ada kejadian ankle sprain berulang dalam 3 bulan di follow up. Dalam studi yang dilakukan De La Motte, Arnold \& Ross ${ }^{17}$, menemukan ada perbedaan pola gerakan dalam rotasi punggung pada star excursion balance exercise yang lebih cenderung menggunakan peningkatan fleksi trunk yang menunjukkan adanya strategi kompensasi untuk mengurangi kontrol postural dengan memanipulasi hip dan trunk.

Fungsional ankle instabil memiliki respon untuk koreksi postur lebih lambat dan dengan cara yang kurang variabel sehingga kemampuan dalam merespon perubahan kontrol postural lemah. ${ }^{18}$ Dalam penanganan fungsional ankle instabil tidak hanya mengatasi sistem sensorimotor lokal saja akan tetapi harus mengatasi sistem sensorimotor global. Sehingga akan menimbulkan respon yang lebih besar dalam perbaikan fungsional ankle instabilitas dan peningkatan keseimbangan dinamis. ${ }^{19}$ Pada penelitian Cug, Duncan and Wikstrom ${ }^{9}$, peningkatan kontrol postural dari latihan keseimbangan hanya terjadi di daerah lokal dari center of pressure velocity, tidak di pusat yang menunjukkan tidak optimal dari kontrol postural.

Penambahan Core Stability pada latihan Star Excursion Balance dapat Meningkatkan Keseimbangan Dinamis Pada Beladiri Taekwondo

Hasil dari studi ini, membuktikan penambahan Core Stability pada Star Excursion Balance Exercise meningkatkan keseimbangan dinamis pada bela diri taekwondo.

Core stabilitas akan mempengaruhi stabilitas dinamis dengan menegangkan dan 
menstabilkan trunk dalam posisi kaku untuk memungkinkan kontrol berat badan. Kontrol ini penting untuk memastikan bahwa pusat gravitasi dalam individu tidak melebihi dasar tumpuan dan menghasilkan keseimbangan. $^{20}$ Menurut Chisthanto ${ }^{21}$, latihan core stability dapat meningkatkan sensitivitas proprioseptif otot-otot core yang merupakan mekanisme sensori utama pada motor kontrol. Peningkatan proprioseptif otot core dapat meningkatkan koordinasi intermuskular dalam respon antisipatif maupun adaptif dan juga dapat meningkatkan mobilitas kerja dari segmen distal yang berguna dalam mempertahankan keseimbangan tubuh.

Dalam studi Kibler ${ }^{11}$, core stability bertindak sebagai dasar dalam gerakan segmen distal dan otot-otot yang bekerja secara sinergis untuk menghasilkan kontrol kekuatan sehingga memberikan stabilisasi dinamis di seluruh rantai kinetik. Didukung dengan penelitian Dhvani \& Varghese ${ }^{22}$, yang berjudul "Effect of Core Stability Training on Dynamic Balance in Healthy Young Adults" menyimpulkan bahwa core stability meningkatkan keseimbangan dinamis melalui kontrol neuromuskuler yang optimal. Core stability meberikan umpan balik propriosepsi yang tepat untuk mempertahankan hubungan panjang otot dan ketegangan otot normal serta kekuatan melalui efek melingkar dari tulang belakang untuk mengontrol sistem saraf keotot dalam mempertahankan keadaan seimbang.

Pada penelitian yang dilakukan Hassan $^{23}$ tentang "The Effect of Core Stability Training on Dynamic Balance and Smash Stroke Performance in Badminton Players" yang meneliti pemain bulu tangkis umur U19 selama 8 minggu. Hasilnya, latihan core stability dapat meningkatkan keseimbangan dinamis dan meningkatkan kemampuan teknik fungsional, kekuatan dan akurasi smash pada pemain bulu tangkis.

\section{Penambahan Core Stability pada Star Excursion Balance Exercise dapat Menurunkan Fungsional Ankle Instabilitas Pada Beladiri Taekwondo}

Berdasarkan hasil dari penelitian ini membuktikan bahwa penambahan Core Stability pada Star Excursion Balance Exercise dapat menurunkan fungsional ankle instabilitas pada bela diri taekwondo.

Stabilitas inti tidak hanya memberi kekuatan dan keseimbangan, tetapi juga membantu dalam menciptakan penyusunan postur antisipatif. Tujuan dari penyusunan postur tersebut untuk memungkinkan stabilitas proksimal membantu pergerakan dari distal melebihi limit keseimbangan tubuh. ${ }^{11}$ Core stability memiliki prinsip mengaktivasi core muscle sebagai komponen stabilisasi pada trunk dan pelvis terhadap pola gerakan extremitas. Aktifnya otot core ini akan menyebabkan terjadinya postural stabilisasi yang berfungsi dalam mekanisme postural kontrol. ${ }^{11}$ Pelatihan ini juga akan menyebabkan peningkatan mekanisme feedback dan feedforward pada fungsi neuromuskular dalam gerakan rantai kinetik di ekstremitas bawah. Hasil tersebut berguna dalam menjaga kontrol postural dari ketidakstabilan fungsional ankle. ${ }^{20}$

Pada studi yang dilakukan oleh Mitchell ${ }^{24}$, tentang ketidakstabilan fungsional ankle menunjukkan single-limb postural sway lebih besar dari yang sehat. Hasil ini menunjukkan defisit postural sway terjadi pada pergelangan kaki dengan FAI akibat perubahan postural pada pergelangan kaki tidak stabil. Pada penelitian Suppiah ${ }^{25}$, tentang "The Effectiveness of A Core Muscles Stability Program in Reducing The Postural Sway of Adolescent Archers: A 
Panacea For A Better Archery Performance" dimana core stability meningkatkan stabilitas melalui peningkatan fungsi susunan saraf pusat untuk merekrut motor unit pada otot. Bukti di sini menunjukkan bahwa pelatihan stabilitas inti dapat mengurangi goyangan postural di antara pemanah remaja. Studi dari Kaji $\mathrm{dkk}^{26}$ dengan judul "Transient Effect of Core Stability Exercises on Postural Sway during Quiet Standing", mendapatkan hasil bahwa core stability exercise secara sementara menurunkan area lintasan Center Of Pressure (COP) dan lintasan mediolateral serta total excursions selama berdiri tenang dengan mata tertutup.

Didukung juga oleh penelitian yang dilakukan oleh Ghasempoor, et al. ${ }^{27}$, latihan core stability efektif dalam meningkatkan pola gerakan fungsional dan kontrol postural dinamis pada atlet perguruan tinggi. Ketahanan otot transversus abdominis memiliki peran penting dalam mengendalikan komponen postural kontrol dalam keseimbangan dan stabilitas tetapi tidak memainkan peran penting dalam komponen orientasi. $^{28}$ Ketika Tranversus abdominis kontraksi akan meningkatkan tekanan intraabdomen dan ketegangan thoraco-lumbal fascia sehingga terjadi postural stabilisasi. Latihan core stabilitas meningkatkan pola aktivitas dan kekuatan otot core salah satunya adalah transversus abdominis. Tranversus abdominis adalah otot pertama yang aktif sebelum gerakan tungkai dan aktivasi yang diprogram sebelumnya dari otot ini merupakan komponen strategi yang digunakan oleh sistem saraf pusat untuk mengontrol stabilitas. $^{29}$

Penambahan Core Stability pada Star Excursion Balance Lebih Meningkatan
Keseimbangan Dinamis daripada Star Excursion Balances Exercise Pada Beladiri Taekwondo

Berdasarkan hasil perbandingan rerata peningkatan keseimbangan dinamis pada penelitian ini membuktikan bahwa penambahan Core Stability pada Star Excursion Balance Exercise lebih meningkatkan keseimbangan dinamis pada bela diri taekwondo.

Penambahan core stability pada star excursion balance exercise meningkatkan keseimbangan dinamis melalui kontrol dinamis dari trunk untuk mempertahankan pusat gravitasi tubuh tidak melebihi dasar tumpuan. Selain itu, core stability meningkatkan proprioseptif dan kontrol motorik untuk respon adaptif maupun respon antisipasi yang berfungsi dalam strategi motorik pada keseimbangan. Core stability juga memberikan umpan balik propriosepsi yang tepat untuk mempertahankan hubungan panjang otot, ketegangan otot dan kekuatan otot melalui efek melingkar dari tulang belakang dalam mengontrol sistem saraf ke otot untuk keseimbangan. Hal ini juga menyebabkan gerakan rantai kinetik lebih fungsional akibat terjadinya efisiensi neuromuskuler dalam akselerasi, deselerasi, dan stabilisasi dinamis pada seluruh rantai kinetik selama gerakan fungsional serta memberikan stabilitas proksimal untuk gerakan ekstremitas bawah yang efisien. Sehingga dengan kombinasi penambahan core stability ini lebih baik karena mempengaruhi komponen dari keseimbangan dinamis secara bersama, bersinergi, dan saling menguatkan.

Penambahan Core Stability pada Star Excursion Balance Exercise Lebih Menurunkan Fungsional Ankle 


\section{Instabilitas daripada Star Excursion Balance Exercise Pada Beladiri Taekwondo}

Berdasarkan hasil perbandingan rerata penurunan fungsional ankle instabilitas pada penelitian ini membuktikan bahwa penambahan Core Stability pada Star Excursion Balance Exercise lebih menurunkan fungsional ankle instabilitas pada bela diri taekwondo.

Penambahan core stability pada Star Excursion Balance Exercise meningkatkan mekanisme feedback dan feedforward pada fungsi neuromuskular dalam gerakan rantai kinetik di ekstremitas bawah yang berguna untuk menjaga kontrol postural dari ketidakstabilan fungsional ankle. Latihan core stability meningkatkan sensitivitas proprioseptif yang menyebabkan terjadinya postural stabilisasi sehingga menciptakan mekanisme postural kontrol dan terjadi kontrol motorik dalam respon adaptif maupun respon antisipasi. Core stability juga menyebabkan terjadinya respon dari proksimal ke distal mengacu pada penguatan otot proksimal yang membantu pencegahan atau penyembuhan pada ankle instability. Selain itu, akan meningkatkan stabilitas melalui peningkatan fungsi susunan saraf pusat untuk merekrut motor unit pada otot dan menurunkan area lintasan Center of Pressure. Latihan core stabilitas akan meningkatkan pola aktivitas dan kekuatan otot core salah satunya adalah transversus abdominis. Ketika Tranversus abdominis kontraksi akan meningkatkan tekanan intraabdomen dan ketegangan thoracolumbal fascia sehingga terjadi postural stabilisasi. Dengan penambahan core stability ini menjadi lebih efektif karena dapat saling meningkatkan dan bersinergi dalam mempengaruhi proprioseptif, postural stabilisasi, postural kontrol dan fungsi otot yang terjadi gangguan pada komponen stabilitas fungsional ankle.

\section{SIMPULAN}

Dari hasil studi tersebut disimpulkan: 1. Penambahan core stability pada star excursion balance exercise lebih meningkatkan keseimbangan dinamis daripada star excursion belance exercises pada bela diri taekwondo.

2. Penambahan core stability pada star excursion balance exercise lebih menurunkan fungsional ankle instabilitas daripada star excursion balance exercise pada bela diri taekwondo.

\section{DAFTAR PUSTAKA}

1. Lystad, RP., Graham, PL., Poulos, RG. 2013. Exposure-Adjusted Incidence Rates And Severity Of Competition Injuries In Australian Amateur Taekwondo Athletes: A 2-Year Prospective Study. Br J Sports Med. 47: 441-446

2. Kazemi, M., Shearer, H. \& Choung, Y.S. 2005. Pre-Competition Habits And Injuries In Taekwondo Athlete. BMC musvuloskeletal disorders, 6(1), 26-29.

3. Fong, D., et al. 2007. A Systematic Review On Ankle Injury And Ankle Sprain In Sports. Sport Medicine, 37 (1), pp. 73-94.

4. Hertel, J. 2002. Functional Anatomy, Pathomechanics, And Pathophysiology Of Lateral Ankle Instability. Journal of Athletic Training. 37(4): 364-375.

5. Ross, SE., Guskiewicz, KM., Yu, B. 2005. Single-Leg Jump-Landing Stabilization Times In Subjects With Functionally Unstable Ankles. J Athl Train.;40(4):298-304. 
6. Eils, E., Rosenbaum, D. 2001. A MultiStation Proprioceptive Exercise Program In Patients With Ankle Instability. Med Sci Sports Exerc.;33:1991-8

7. Olmsted, LC., et al. 2002. Efficacy Of Star Excursion Balance Tests In Detecting Reach Deficits In Subjects With Chronic Ankle Instability. J Athl Train.;37:501-606

8. Chaiwanichsiri, D., Lorprayoon, E., Noomanoch, L. 2005. Star Excursion Balance Training :Effect On Ankle Functional Stability After Ankle Sprain. J Med Assoc Thai.;88 (suppl 4): S90-4

9. Cug, M., Duncan, A., Wikstrom, E. 2016. Comparative Effect of Different Balance Training Progression Styles on Postural Control and Ankle Force Production: A Randomized Controlled Trial. J. Athl Train. 51(2): 101-110

10. Hiller, C. E., Kilbreath, S. L., \& Refshauge, K. M. 2011. Chronic Ankle Instability: Evolution Of The Model. Journal of Athletic Training. 46(2): 133141.

11. Kibler WB Press J and Sciascia A. 2006. The Role of Core Stability in Athletic Function. Sports Medicine. 36(3): p. 198-198

12. Mandarakas, M., Pourkazemi, F., Sman, A., Burn, J., Hiller, C.E. 2014. Systematic Review of CAI in Childern. Journal of Foot and Ankle. 7:21

13. Centre for Obesity Research and Education. 2007. Body Mass Index: BMI Calculator. Diakses dari: http://www.core.monash.org/bmi.html tanggal 18 januari 2019.

14. Efendi, Nur. 2006. "Sumbangan Indeks Massa Tubuh, Daya Ledak Otot Lengan, Daya Ledak Otot Torsio Togok dan Daya Ledak Otot Tungkai Terhadap Hasil Tolak Peluru Gaya O’brien Pada
Mahasiswa Ilmu Keolahragaan Angkatan Tahun 2005” (skripsi). Universitas Negeri Malang

15. Gribble, P. A., Hertel, J., \& Plisky, P. 2012. Using the Star Excursion Balance Test to assess dynamic postural-control deficits and outcomes in lower extremity injury: a literature and systematic review. Journal of athletic training. 47(3), 339-357.

16. Reza, S.H., Nader, R., Effat, B., Maryam, K. 2014. The Effect of Star Excursion Balance Training on Ankle Sprain Injury Rehabilitation. Journal of Research in Rehabilitation Sciences. Vol. 10(1); 123-130.

17. De La Motte, S., Arnold, B. L., \& Ross, S. E. 2015. Trunk-rotation differences at maximal reach of the star excursion balance test in participants with chronic ankle instability. Journal of athletic training, 50(4), 358-365.

18. Hertel, J., Olmsted-Kramer, L., Challis, J. 2006. Time-to-Boundary Measures of Postural Control during Quiet Single Leg Standing. J. Appl Biomech. 22: 6773.

19. McKeon, P. O., \& Hertel, J. 2008. Systematic Review Of Postural Control And Lateral Ankle Instability, Part I: Can Deficits Be Detected With Instrumented Testing. Journal of Athletic Training. 43(3): 293-304.

20. Zazulak, BT. Hewett, TE. Reeves, NP. Goldberg, B. and Cholewicki J. 2007. The Effects of Core Proprioception on Knee Injury: A Prospective Biomechanical Epidemiological Study. The American Journal of Sports Medicine. 35(3): p. 368-373.

21. Christhanto, D.A., Adiputra, N., Lesmana, S.I., Sutjana, A.P., Muliarta, M., \& Wahyudin. W. 2017. 
Penamnbahan Latihan Core Stability Pada Program Pelatihan Atlet Dayung Untuk Peningkatan Kecepatan Mendayung. Sport and Fitness Journal.;5(3):40-47

22. Dhvani, N. Shah \& Varghese, Annamma. 2014. Effect Of Core Stability Training On Dynamic Balance In Healthy Young Adults - A Randomized Controlled Trial. International Journal of Physiotherapy,1(4), 187-194.

23. Hassan, I.A.I. 2017. The Effect of Core Stability Training on Dynamic Balance and Smash Stroke Performance in Badminton Players. International Journal of Sports Science and Physical Education. Vol. 2, No. 3, pp.44-52

24. Mitchell, A., Dyson, R., Hale, T., Abraham, C. 2008. Biomechanics of ankle instability. Part 2: Postural swayreaction time relationship. Med $\mathrm{Sci}$ Sports Exerc. Aug; 40(8):1522-8.)

25. Suppiah, P., Kee Kiet, T., Musa, R., Abdullah, M., Lee, J. L., \& Maliki, A. H. 2017. The Effectiveness Of A Core Muscles Stability Program In Reducing The Postural Sway Of Adolescent Archers: A Panacea For A Better Archery Performance. International Journal of Physiotherapy. 4(5), 296-301.

26. Kaji, A Sasagawa., S. Kubo, T., and Kanehisa H. 2010. Transient Effect of Core Stability Exercises on Postural Sway During Quiet Standing. Journal of Strength and Conditioning Research. 24(2): p. 382-338.

27. Ghasempoor, K., Rahnama, N., Bagherian, S., et al. 2017. P18 The effect of core stability training on functional movement patterns in collegiate athletes.
British Journal of Sports Medicine;51:A19-A20.

28. Anoli, J.H. \& Jhon, S. 2018. Correlation Between Transversus Abdominis Muscle Endurance and Limits of Stability in Asymptomatic Healthy Young Woman. International Journal of Physiotherapy. 5(3), 123-131

29. Cholewicki, j., Van Vliet JJ4th. 2002. Relative Contribution of Trunk Muscle to the Stability of the Lumbar Spine during Isometric Exertions. Clin Biomech. 17(2): 99-105. 